\title{
Is Lymphadenectomy a Predictor or Savior for Patients with Gastric Cancer?
}

\author{
Hiroya Takeuchi, MD, PhD and Yuko Kitagawa, MD, PhD, FACS \\ Department of Surgery, Keio University School of Medicine, Tokyo, Japan
}

In the history of surgical oncology, survival benefit of extended lymphadenectomy has been a focus of debates in gastrointestinal carcinomas. ${ }^{1}$ The fear for the invisible metastasis prompted surgeons to perform more aggressive resections with lymphadenectomy to control the disease locally. However, the clinical significance of extended lymphadenectomy has been the subject of controversy over the past 10 years. $^{2-4}$ On the other hand, the histopathological status of regional lymph nodes is one of the most reliable predictors of recurrence and overall survival for most gastrointestinal cancer, and it is often used to justify stratification of patients for adjuvant therapy.

Gastric cancer is the second leading cause of cancer death worldwide; it is particularly common in Asian countries, including Japan. To date, several classifications of lymph node metastasis is considered for patients with gastric cancer. Classification was based on the anatomical location of nodal involvement has been established in the Japanese Gastric Cancer Association. The total number of involved lymph nodes is also considered as the $\mathrm{N}$ status defined by the American Joint Committee on Cancer (AJCC) and the International Union Against Cancer (UICC). In the 5th and 6th editions of the AJCC/UICC tumor, node, metastasis system (TNM) classification, the $\mathrm{N}$ status for gastric cancer was defined as follows: N0, no regional lymph node metastasis; N1, metastasis in 1-6 regional lymph nodes; N2, metastasis in 7-15 regional lymph nodes; and $\mathrm{N} 3$, metastasis in $\geq 16$ regional lymph nodes. On the other hand, in the most recent UICC TNM staging system (7th edition) redefined $\mathrm{N}$ status is categorized into N0, no regional lymph node metastasis; N1, metastasis in 1-3 regional lymph nodes; N2, metastasis in

(C) Society of Surgical Oncology 2010

Published Online: 6 February 2010

H. Takeuchi, MD, PhD

e-mail: htakeuch@sc.itc.keio.ac.jp
4-6 regional lymph nodes; N3a, metastasis in 7-15 regional lymph nodes; and $\mathrm{N} 3 \mathrm{~b}$, metastasis in $\geq 16$ regional lymph nodes. A recent article by Deng et al. indicated that the 7 th edition UICC $\mathrm{N}$ status would provide more reliable prognostic information than the 5th/6th edition UICC $\mathrm{N}$ status by analysis of the 456 patients with gastric cancer after curative surgery. ${ }^{5}$ However, $\mathrm{N}$ status by the AJCC/ UICC TNM staging is restricted by regional lymphadenectomy, in which at least 15 lymph nodes should be examined, because stage migration that results from the number of dissected lymph nodes is frequently recognized as one of the major concerns in the AJCC/UICC staging system for gastric cancer.

Recent investigations have emphasized the clinical utility of a new lymph node staging ( $\mathrm{N}$ ratio) that is based on the number of positive lymph nodes divided by the number of examined lymph nodes. ${ }^{6,7}$ Inoue et al. showed that the $\mathrm{N}$ ratio was the most statistically significant prognostic factor, whereas the $\mathrm{N}$ status by the AJCC/UICC staging system was not found to be significant by multivariate analysis of the 1019 patients with gastric cancer who underwent R0 resection. ${ }^{6}$ Recently Bando et al. also reported that the $\mathrm{N}$ ratio was well correlated with prognosis for 777 patients with advanced gastric cancer, as an independent prognostic factor in a multivariate analysis. ${ }^{7}$ Moreover, the $\mathrm{N}$ ratio was a statistically significant prognostic factor in N1, N2, and N3 patients defined by the Japanese classification of disease.

The current article by Maduekwe et al. reports on the $\mathrm{N}$ ratio in 257 patients undergoing D1 lymphadenectomy for gastric cancer. ${ }^{8}$ The authors note that there was no statistically significant difference in overall survival between patients with $<15$ and $\geq 15$ nodes examined when they stratified $\mathrm{N}$ ratio intervals. They concluded that the $\mathrm{N}$ ratio is more reliable as a prognostic indicator minimizing stage migration compared to the $\mathrm{N}$ status by the 6th edition AJCC/UICC TNM staging system, even in patients with 
D1 lymphadenectomy in which $<15$ lymph nodes were excised. The article may represent a valuable signpost for the future direction of the lymph node staging system. If the $\mathrm{N}$ ratio is really feasible even to the patients with $\mathrm{D} 1$ lymphadenectomy, discrepancy in prognosis of gastric cancer patients between Japan and Western countries, which is partly believed to be the result of stage migration, could be avoided. However, its results should be interpreted in context with caution. First, the authors set up a unique category, $\mathrm{Nr} 0$, which was designated only for patients with no lymph node metastasis among $\geq 15$ lymph nodes examined, but not for patients with $<15$ nodes. If $\mathrm{Nr} 0$ disease was indicated even in patients with $<15$ nodes examined, the survival of patients with $\mathrm{Nr} 0$ and $\mathrm{Nr} 1$ disease who had $<15$ nodes examined might be much worse than that $\mathrm{Nr} 0$ and $\mathrm{Nr} 1$ disease in patients with $\geq 15$ nodes, respectively. Is their stratification universally applicable to every institution in the world?

Second, unfortunately, the current article from Maduekwe et al. was based on the retrospective review of a smaller number of patients compared to previous reports. $^{6-9}$ Sun et al. recently showed the similar results that the $\mathrm{N}$ ratio has advantages in minimizing stage migration for patients with insufficient number of lymph nodes excised or patients with D1 lymphadenectomy from their series of 2159 patients with gastric cancer. ${ }^{9}$ Because the study of Maduekwe et al. was also mentioned in the article, the new $\mathrm{N}$ ratio stratification should be validated by a large prospective study in the future. ${ }^{8}$

Third, are there any therapeutic effects of extended lymphadenectomy or resection of more lymph nodes? In Japan and other Asian countries, extensive (D2) lymphadenectomy has been performed as standard procedures for mid to advanced gastric cancer because it is believed that extensive lymphadenectomy is effective in controlling the disease locally. To date, two large European randomized trial that compared D1 with D2 lymphadenectomy, the Dutch trial and British Medical Research Council Trial, both failed to show a survival benefit in the favor of D2 dissection. ${ }^{2,3}$ However, these trials have been criticized for poor quality of surgical techniques and extremely high mortality rate (10 and 13\%) after D2 lymphadenectomy. If D2 lymphadenectomy is performed with low morbidity and mortality, it is likely to have a marked benefit compared to D1 lymphadenectomy. ${ }^{2,3,10}$ A recent Taiwanese trial comparing D1 with $\mathrm{D} 2+\alpha$ proved a modest survival benefit for $\mathrm{D} 2+\alpha$ dissection over D1, with statistical significance, although the trial had several issues to resolve. ${ }^{4}$

Clinical benefit of D1/D2 lymphadenectomy for gastric cancer in terms of accurate staging and locoregional control should be validated by carefully designed multicenter prospective randomized trials in Western and/or Asian countries. Further exploration may clarify where it should be positioned in surgical oncology for gastric cancer.

\section{REFERENCES}

1. Takeuchi H, Kitajima M, Kitagawa Y. Sentinel lymph node as a target of molecular diagnosis of lymphatic micrometastasis and local immunoresponse to malignant cells. Cancer Sci. 2008; 99:441-50.

2. Binenkamp JJ, Hermans J, Sasako M, et al. Extended lymph-node dissection for gastric cancer. N Engl J Med. 1999;340:908-14.

3. Cuschieri A, Weeden S, Fielding J, et al. Patients survival after D1 and D2 resections for gastric cancer: long-term results of the MRC randomized surgical trial. Surgical Co-operative Group. $\mathrm{Br}$ J Cancer. 1999;79:1522-30.

4. Wu CH, Hsiung CA, Lo SS, et al. Nodal dissection for patients with gastric cancer: a randomized controlled trial. Lancet Oncol. 2006;7:309-15.

5. Deng J, Liang H, Sun D, et al. The 7th UICC N stage is suitable for prediction the overall survival of gastric cancer patients after curative resection in China. Ann Surg Oncol. 2010; (in press).

6. Inoue $\mathrm{K}$, Nakane $\mathrm{Y}$, Iiyama $\mathrm{H}$, et al. The superiority of ratiobased lymph node staging in gastric carcinoma. Ann Surg Oncol. 2002;9:27-34.

7. Bando E, Yonemura Y, Taniguchi K, et al. Outcome of ratio of lymph node metastasis in gastric carcinoma. Ann Surg Oncol. 2002;9:775-84.

8. Maduekwe U, Lauwers G, Fernandez-del-Castillo C, et al. A new metastatic lymph node ratio system reduces stage migration inpatients undergoing D1 lymphadenectomy for gastric adenocarcinoma: analysis of 257 consecutive cases at a single Western institution. Ann Surg Oncol. 2010; (in press).

9. Sun Z, Zhu GL, Lu C, et al. The impact of N-ration in minimizing stage migration phenomenon in gastric cancer patients with insufficient number or level of lymph node retrieved: results from a Chinese mono-institutional study in 2159 patients. Ann Oncol. 2009;20:897-905.

10. Sasako M, Saka M, Fukagawa T, et al. Modern surgery for gastric cancer. Japanese perspective. Scand J Surg. 2006;95:232-5. 